\title{
Note
}

\section{Effects of Hydroxypropyl Methylcellulose and Temperature of Dough Water on the Rice Noodle Quality}

\author{
Jung A Ko ${ }^{1}$, Hyung Sun $\mathrm{KIM}^{1,2}$, Hyun Ho BAEK ${ }^{3}$ and Hyun Jin PARK ${ }^{1,4^{*}}$ \\ ${ }^{I}$ School of Life Sciences and Biotechnology, Korea University, Seoul, 136-701, Korea \\ ${ }^{2}$ CJ CheilJedang Food Research Center, Seoul, 152-051, Korea \\ ${ }^{3}$ Food \& Pharma Ingredient R\&D Team, Samsung Fine Chemicals, Incheon, Korea \\ ${ }^{4}$ Department of Packaging Science, Clemson University, Clemson, SC 29634-0370, USA
}

Received January 6, 2014 ; Accepted September 19, 2014

\begin{abstract}
Rice noodle is one of the most popular foods consumed in Asia. However, rice flour lacks gluten that forms a cohesive dough structure in wheat-based noodles and for gluten-free, rice-based noodle formulations an alternative to gluten is needed. Therefore, the effects of the addition of hydroxypropyl methylcellulose (HPMC) as a replacement for gluten and the temperature of the water used for rice noodle preparation were investigated. Rice noodle contained high-viscosity HPMC (6\%) had the smallest breakdown and the largest setback viscosity, also had better texture and sensory properties. The use of dough water at $80^{\circ} \mathrm{C}$ was effective on reducing the cooking loss and improving the textural properties. The overall acceptability score was higher compared to that of the control. The results showed that using high-viscosity HPMC $(6 \%)$ to replace gluten and kneading with water at $80^{\circ} \mathrm{C}$ was the most effective protocol for improving the quality of gluten-free rice noodles.
\end{abstract}

Keywords: rice noodle, hydroxypropyl methylcellulose, HPMC, texture properties

\section{Introduction}

Noodles have long been a staple food owing to the ease and convenience in using them. They form an essential part of our diet and are one of the most popular processed foods (Li et al., 2012). Traditional noodles are made from flour, water, and salt. Wheat flour, the primary ingredient for making noodles, is most widely used because gluten contributes to the viscoelasticity of the dough and overall texture (Jung et al., 2009). However, gluten is associated with celiac disease, which is caused by susceptibility to the gliadin fraction of wheat gluten and similar alcohol-soluble proteins of barley and rye. An immune reaction in the small intestine damages the mature absorptive epithelial cells and results in diarrhoea, abdominal pain, and growth disorders (Murray, 1999; Gallagher et al., 2004; Moore et al., 2006). Many studies are now focusing on processing gluten-free rice noodles, and developing special rice for those suffering from celiac disease (Bean and Nishita, 1985; Huang et al., 2001; Yalcin and Basman, 2008). Rice noodle is one of the most popular varieties of traditional oriental food widely consumed in Southeast Asia. However, the greatest difficulty in processing rice noodles is the preparation of rice flour dough as rice flour lacks the substance that allows gluten to form a mesh-like structure (Kulp et al., 1974). To overcome this problem, recent studies have attempted to find a replacement for gluten, and to make rice noodle by adding hydroxypropyl methylcellulose (HPMC), locust bean gum, guar gum, carrageenan, xanthan gum, agar, and starch (corn, cassava, and potato) (Marco and Rosell, 2008; Yalcin and Basman, 2008).

Hydroxypropyl methylcellulose (HPMC) is obtained by the addition of methyl and hydroxypropyl groups to the cellulose chain, leading to a polymer with a high surface activity. It has 
Table 1. Chemical properties of HPMC

\begin{tabular}{ccccc}
\hline Name & $\begin{array}{c}\text { Viscosity } \\
(\mathrm{cP})\end{array}$ & $\begin{array}{c}\text { Molecular } \\
\text { weight } \\
(\mathrm{MW})\end{array}$ & $\begin{array}{c}\text { Degree of } \\
\text { Substitution } \\
(\mathrm{DS})\end{array}$ & $\begin{array}{c}\text { Degree of } \\
\text { polymerization } \\
(\mathrm{DP})\end{array}$ \\
\hline L-HPMC & 4,000 & $423,350 \pm 4083^{\mathrm{c}}$ & $1.46 \pm 0.02^{\mathrm{a}}$ & $570 \pm 17^{\mathrm{c}}$ \\
M-HPMC & 15,000 & $504,800 \pm 2316^{\mathrm{b}}$ & $1.46 \pm 0.01^{\mathrm{a}}$ & $740 \pm 10^{\mathrm{b}}$ \\
H-HPMC & 100,000 & $843,200 \pm 6792^{\mathrm{a}}$ & $1.49 \pm 0.01^{\mathrm{a}}$ & $1250 \pm 10^{\mathrm{a}}$ \\
\hline
\end{tabular}

L means Low, $\mathrm{M}$ means Medium, and $\mathrm{H}$ means High viscosity level.

${ }^{a-c}$ Means with same letter within a column indicate no significant difference $(\mathrm{p}<0.05)$.

hydration-dehydration characteristics in the solution state and during temperature changes. HPMC is capable of various functions such as emulsification, reinforcement, moisturization, shape preservation, and gelation (Bell, 1990; Lee et al., 2010). Because HPMC undergoes a gel-sol phase transition with changes in temperature, it is able to form a mesh-like structure based on mutual reactions between hydrophobic functional groups. HPMC preserves its gel state under a certain range of temperature, making HPMC a suitable substitute for gluten in rice noodle processing (Lee et al., 2010). Furthermore, HPMC is a soluble dietary fiber that enhances insulin efficiency and cholesterol synthesis by facilitating bowel movements and lowering the rate of fat absorption (Kim et al., 2011). This reduces the glycemic index (GI) of the noodles, and, thus, helps prevent obesity and diabetes (Jeya, 2001). Moreover, research is underway for pasta (Purnima, 2012), instant noodles (Farzi et al., 2013), and bread (Marco and Rosell, 2008; Kim and Yokoyama, 2011; Sabanis and Tzia, 2011). HPMC is especially one of the most suitable to improve the volume and texture of the rice bread. However, only limited information is reported about HPMC effects in the rice noodle.

The objective of this study was to prepare rice noodles using HPMC as a substitute for gluten and to investigate their physical and cooking properties. As a method of improving rice noodle quality, the effects of addition of HPMC at various viscosities and the temperature of the water used for dough preparation were studied.

\section{Materials and Methods}

Materials Rice (Goami, amylose content: 27\%) was obtained from the Rural Development Administration (Suwon, Korea) and ground into flour by air classifier mill system (Inchon, Korea). Three types of HPMC (AnyAddy ${ }^{\circledR}$ ) were donated by Samsung Fine Chemicals Co., Ltd (Gyeonggi-do, Korea). The specifications of each HPMC type are listed in Table 1.

Pasting properties The pasting properties of rice flour samples were studied using a Rapid Visco Analyzer (RVA; NewPort Scientific Instruments \& Engineer, Australia). HPMC (L-HPMC, $\mathrm{M}-\mathrm{HPMC}$, or H-HPMC) was added to the rice flour at $0 \%, 2 \%$, $4 \%$, and $6 \%(\mathrm{w} / \mathrm{w})$, respectively. Flour ( $3 \mathrm{~g}, 14 \%$ moisture $)$ was directly weighed in the aluminum RVA sample canister, and distilled water was added to a total constant sample weight of $28 \mathrm{~g}$. A programmed heating-and-cooling cycle was used, where the samples were held at $50^{\circ} \mathrm{C}$ for $1 \mathrm{~min}$, heated to $95^{\circ} \mathrm{C}$ for $7.5 \mathrm{~min}$ at a rate of $6^{\circ} \mathrm{C} / \mathrm{min}$, held at $95^{\circ} \mathrm{C}$ for $5 \mathrm{~min}$ before cooling to $50^{\circ} \mathrm{C}$ in $7.5 \mathrm{~min}$, and then maintained at $50^{\circ} \mathrm{C}$ for $1 \mathrm{~min}$. Breakdown (peak viscosity-through viscosity) and setback values (final viscosity peak viscosity) were calculated from the pasting curve (Meadows and Barton, 2002; Rosell et al., 2011). All tests were replicated 3 times.

Preparation of the rice noodles Rice noodles were prepared (rice flour $282 \mathrm{~g}$, HPMC $18 \mathrm{~g}$ and water $210 \mathrm{~mL}$ ) using a mixer (Model 555; KitchenAid, Inc. St. Joseph, MI, USA) for $10 \mathrm{~min}$. The temperature of the water used to knead the dough was either room temperature or $80^{\circ} \mathrm{C}$. The dough was packed in plastic bags and rested at room temperature for $60 \mathrm{~min}$. The dough was passed through the reduction rolls of a pasta machine (Atlas Pasta Machine, Italy) to produce uniform noodles (length, $20 \mathrm{~cm}$; width, $3 \mathrm{~mm}$; thickness, $2 \mathrm{~mm}$ ). Noodles containing $11.5 \%$ (w/w) gluten were used as the control and the amount of gluten was adjusted to the gluten content in medium wheat flour. Control rice noodles were kneaded with room temperature water by the above method.

Texture analysis The texture of the rice noodles was analyzed within 15 min by using a texture analyzer (TA-XT2; Texture Technologies Corp., Scarsdale, NY, USA). Ten grams of noodles from each experimental group were boiled separately in $200 \mathrm{~mL}$ of distilled water for $5 \mathrm{~min}$, drained, weighed, and used for studying the textural properties of the cooked noodles. The measurements were completed within 10 min after cooking.

A strand of cooked noodle $(5 \mathrm{~cm})$ with $2 \mathrm{~mm}$ thickness was placed on a flat metal plate and compressed using a cylinder probe (diameter, $20 \mathrm{~mm}$ ). The pressing depth was $50 \%$ of the sample thickness. The settings of the texture analyzer were pre-test speed of $1.0 \mathrm{~mm} / \mathrm{s}$, test speed of $1.0 \mathrm{~mm} / \mathrm{s}$, and post-test speed of $1.0 \mathrm{~mm} /$ s. From the force-time curve of the texture profile, textural parameters, including hardness, chewiness, springiness, and cohesiveness, were determined

For testing tensile strength, a strand of cooked noodle was held in tensile grip by the texture analyzer. The noodles were placed one end into the lower arm of grip and the other end to upper arm. The upper arm was set to travel apart from the lower arm at the test 
Table 2. Effects of HPMC on the pasting properties of rice flour

\begin{tabular}{cccc}
\hline Sample & $\begin{array}{c}\text { HPMC Conc. } \\
(\%)\end{array}$ & Breakdown (cP) & Setback (cP) \\
\hline Rice flour & 0 & $252 \pm 10.0$ & $35.3 \pm 3.4$ \\
\hline Rice flour & 2 & $238.2 \pm 8.93^{\mathrm{a}}$ & $200.7 \pm 4.14^{\mathrm{c}}$ \\
+ L-HPMC & 4 & $198.6 \pm 11.0^{\mathrm{b}}$ & $269.1 \pm 4.06^{\mathrm{b}}$ \\
& 6 & $93.6 \pm 13.16^{\mathrm{c}}$ & $344.9 \pm 17.65^{\mathrm{a}}$ \\
\hline & 2 & $269.3 \pm 5.33^{\mathrm{a}}$ & $175.9 \pm 5.26^{\mathrm{c}}$ \\
+ Rice flour & 4 & $170.3 \pm 1.11^{\mathrm{b}}$ & $266.4 \pm 9.04^{\mathrm{b}}$ \\
+ M-HPMC & 6 & $92.5 \pm 8.21^{\mathrm{c}}$ & $342.3 \pm 15.81^{\mathrm{a}}$ \\
\hline & 2 & $230.0 \pm 8.18^{\mathrm{a}}$ & $203.9 \pm 8.57^{\mathrm{c}}$ \\
$\begin{array}{c}\text { Rice flour } \\
+ \text { H-HPMC }\end{array}$ & 4 & $128.9 \pm 3.47^{\mathrm{b}}$ & $298.4 \pm 8.25^{\mathrm{b}}$ \\
& 6 & $50.8 \pm 7.07^{\mathrm{c}}$ & $411.7 \pm 5.76^{\mathrm{a}}$ \\
\hline a-c & Means with same letter within a column indicate no significant difference \\
$(\mathrm{p}<0.05)$. & &
\end{tabular}

speed of $1.0 \mathrm{~mm} / \mathrm{s}$ with a rupture distance of $40 \mathrm{~mm}$. The maximum force $(\mathrm{g})$ required to break the cooked rice noodle strand gave an indication of sample resistance to the breakdown and the distance $(\mathrm{mm})$ to break indicated its extensibility. The measurements were repeated 10 times for each sample.

\section{Cooking properties}

Water absorption: Samples of the rice noodles (10 g) were placed into $200 \mathrm{~mL}$ of boiling distilled water for $5 \mathrm{~min}$. The boiled noodle samples that were removed from the cooking water were drained for $3 \mathrm{~min}$ and then weighed. Water absorption was expressed as the ratio of the mass of the noodle after and before cooking.

Water absorption $(\%)=$

Weight of cooked noodle $(\mathrm{g})$ - Weight of uncooked noodle $(\mathrm{g})$ Weight of uncooked noodle $(\mathrm{g})$ $\times 100$

Cooking loss: The boiled noodles were removed (see above) and the cooking water was collected in a beaker pre-dried to a constant weight. The beaker was placed into an air oven at $105^{\circ} \mathrm{C}$ and evaporated to dryness. The residue was weighed and reported as a percentage of the starting material (calculated on the basis of dry weight).

Sensory evaluation Sensory analysis was carried out after cooking the noodle samples. The noodles were cut into $15 \mathrm{~cm}$ pieces and boiled for $10 \mathrm{~min}$ and cooling them to room temperature. Then the cooked noodles were served in dishes randomly labeled with 3-digit random numbers. The sensory evaluation of the noodle samples were evaluated by 10 trained panelists by using a 9-point hedonic scale with "9" denoting "liked extremely" and "1" denoting "disliked extremely". The sensory properties evaluated included color, odour, texture, taste, appearance and overall acceptability. The panelists were asked to rinse their mouths with water between each sample.

Statistical analysis All data obtained in this study were analyzed by Duncan's Multiple Comparison Method by using the Statistical Analysis System (SAS Institute Inc., Cary, NC, USA). Significance was determined at $p<0.05$ for all analysis. At least 3 replications were made for each measurement.

\section{Results and Discussion}

Properties of HPMC-containing rice dough Table 2 shows the RVA measurements taken of three different levels of viscosity (L-HPMC, M-HPMC, and H-HPMC) for samples containing $2 \%$, $4 \%$, and $6 \%$ HPMC, respectively. The production of rice noodles is difficult because of the lack of gluten. Gluten is the major structure-forming protein responsible for the viscoelastic properties of dough, and it contributes to the texture and appearance of the end products (Yalcin and Basman, 2008). When rice is used as the only material to prepare noodle-like products, it requires some starch gelatinization to play the role of a binder (Lai, 2002). Therefore, HPMC was added to produce the rice noodles, and the breakdown and the setback viscosity of rice dough were observed.

A comparison of sample characteristics according to concentration levels revealed that breakdown viscosity significantly decreased as the concentration of HPMC increased from $2 \%$ to $6 \%$. For samples containing 6\% HPMC, the breakdown values of L-HPMC, M-HPMC, and H-HPMC were the lowest at 93.6, 92.5, and $50.8 \mathrm{cP}$, respectively. H-HPMC, the sample with highest viscosity, had the lowest breakdown viscosity. Breakdown viscosity is a measurement of the susceptibility of cooked starch to disintegration. In addition, breakdown viscosity is one of the most important attributes of starch pastes that led to the widespread use of chemical cross-linking of starch to reduce paste breakdown. Lower breakdown viscosity reflects higher stability of the starch granule and less soluble starch (Cham and Suwannaporn, 2010).

Setback viscosity measures the degree of hardening of cooked starch during cooling (Yang and Tao, 2008). When setback viscosity is low, rice noodles do not turn sufficiently hard during 
Table 3. Texture profile analysis of rice noodles with HPMC

\begin{tabular}{|c|c|c|c|c|c|c|}
\hline & & Hardness (g) & Springiness (mm) & Chewiness & Cohesiveness & Tensile strength $(\mathrm{g} / \mathrm{s})$ \\
\hline Control $^{1)}$ & & ${ }^{\mathrm{A}} 384.1 \pm 3.77$ & ${ }^{\mathrm{A}} 0.78 \pm 0.07$ & ${ }^{\mathrm{A}} 306.57 \pm 4.00$ & ${ }^{\mathrm{A}} 0.76 \pm 0.02$ & ${ }^{\mathrm{A}} 504.2 \pm 2.9$ \\
\hline \multirow{2}{*}{ L-HPMC $^{2)}$} & $\mathrm{RT}^{3)}$ & $185.1 \pm 1.88^{\mathrm{b}}$ & $0.69 \pm 0.05^{\mathrm{a}}$ & $87.81 \pm 4.98^{\mathrm{b}}$ & $0.68 \pm 0.03^{\mathrm{a}}$ & $195.1 \pm 1.7^{b}$ \\
\hline & $80^{\circ} \mathrm{C}$ & ${ }^{\mathrm{C}} 272.4 \pm 4.28^{\mathrm{a}}$ & ${ }^{\mathrm{B}} 0.71 \pm 0.08^{\mathrm{a}}$ & ${ }^{\mathrm{D}} 139.19 \pm 3.37^{\mathrm{a}}$ & ${ }^{\mathrm{C}} 0.69 \pm 0.03^{\mathrm{a}}$ & ${ }^{\mathrm{D}} 288.2 \pm 3.8^{\mathrm{a}}$ \\
\hline \multirow{2}{*}{ M-HPMC } & RT & $232.7 \pm 3.20^{\mathrm{b}}$ & $0.70 \pm 0.05^{\mathrm{b}}$ & $108.40 \pm 5.77^{\mathrm{b}}$ & $0.66 \pm 0.02^{\mathrm{b}}$ & $214.6 \pm 1.7^{b}$ \\
\hline & $80^{\circ} \mathrm{C}$ & ${ }^{\text {в }} 334.7 \pm 5.71^{\text {а }}$ & ${ }^{\mathrm{AB}} 0.74 \pm 0.02^{\mathrm{a}}$ & ${ }^{\mathrm{C}} 171.26 \pm 3.65^{\mathrm{a}}$ & ${ }^{\mathrm{BC}} 0.70 \pm 0.02^{\mathrm{a}}$ & ${ }^{\mathrm{C}} 300.0 \pm 2.6^{\mathrm{a}}$ \\
\hline \multirow{2}{*}{ H-HPMC } & RT & $236.8 \pm 4.37^{b}$ & $0.71 \pm 0.05^{\mathrm{b}}$ & $112.57 \pm 5.00^{\mathrm{b}}$ & $0.67 \pm 0.03^{b}$ & $291.3 \pm 3.1^{b}$ \\
\hline & $80^{\circ} \mathrm{C}$ & ${ }^{\mathrm{A}} 382.0 \pm 4.70^{\mathrm{a}}$ & ${ }^{\mathrm{AB}} 0.76 \pm 0.04^{\mathrm{a}}$ & в $205.57 \pm 2.92^{\mathrm{a}}$ & ${ }^{\mathrm{B}} 0.72 \pm 0.03^{\mathrm{a}}$ & ${ }^{\text {в }} 333.1 \pm 1.6^{\mathrm{a}}$ \\
\hline
\end{tabular}

\footnotetext{
${ }^{1)}$ control: rice flour + gluten.

${ }^{2)}$ Rice noodles contain 6\% HPMC.

${ }^{3)}$ The temperature of the water used to knead the dough was either room temperature (RT) or $80^{\circ} \mathrm{C}$.

${ }^{a-c}$ Means with same letter within a column indicate no significant difference $(\mathrm{p}<0.05)$.

${ }^{\mathrm{A}-\mathrm{D}}$ Comparison between control and samples of water temperature of $80^{\circ} \mathrm{C}$. Means with same letter within a column indicate no significant difference $(\mathrm{p}<0.05)$.
}

the ripening period, leading to a less intricate structure. If rice flour is used without gluten, proper noodle production is nearly impossible because the resulting strands will have poor viscoelasticity and it will tend to break into pieces. From this experiment, we observed that the setback viscosity increased as HPMC concentration rose from $2 \%$ to $6 \%$, and the noodles gained elasticity. Because rice noodles with low setback viscosity break easily, we continued to use 6\% HPMC for further experiments, which was associated with high setback viscosity and low breakdown viscosity. Rosell et al. (2011) had also found that increasing concentration of HPMC in rice starch resulted in lower breakdown viscosity and higher setback viscosity.

Texture profile analysis of rice noodles containing HPMC Texture property of cooked noodles is one of the most important characteristics that determines consumer acceptance of the product (Bhattacharya et al., 1999). Table 3 displays the texture profiles of the rice noodles obtained using dough water at 2 different temperatures (room temperature and $80^{\circ} \mathrm{C}$ ) and after adding 3 types (L-HPMC, M-HPMC, and H-HPMC) of 6\% HPMC solutions. Rice noodles containing H-HPMC had higher values for springiness, hardness, chewiness and tensile strength compared to those containing L-HPMC.

Raina et al. (2005) reported that the hydrophilic components of hydrocolloids interact with proteins because of ionic charges and improve the structure of the pasta. HPMC has water-retention properties because of its hydrophilic nature. HPMC also contains hydrophobic groups, which induce additional properties, including increased interfacial activity within the dough system and formation of gel networks when heated during noodle manufacturing (Lazaridou et al., 2007).

Regarding the temperature of dough water, higher values for hardness, springiness, cohesiveness, chewiness and tensile strength were observed for samples prepared using dough water at $80^{\circ} \mathrm{C}$ compared to samples prepared using water at room temperature.
HPMC exists in the sol state at low temperatures, but it gels at $63-80^{\circ} \mathrm{C}$, during which mutual reactions or interactions between the hydrophobic functional groups create a mesh-like structure and jelly-like coating layer (Lee et al., 2010). Processing suitability improved when the dough water was at $80^{\circ} \mathrm{C}$ and not at room temperature.

One of the critical quality problems of rice noodles, when compared to wheat noodles, is the mushy texture of the cooked noodles (Han et al., 2011). In these experiments, we found that noodle hardness increased with higher values of HPMC viscosity due to the strong gel matrix formed. And the degree of increase was greater for noodles prepared using dough water at $80^{\circ} \mathrm{C}$. The chewiness is the product of hardness, springiness, cohesiveness and therefore influenced by the change in these parameters. In this experiment, chewiness showed a tendency to increase with increasing hardness. Also, the tensile strength, which indicates how the sample holds together during cooking, was increased by addition the high viscosity HPMC and dough water at $80^{\circ} \mathrm{C}$. Noodles prepared with $6 \% \mathrm{H}$-HPMC and dough water at $80^{\circ} \mathrm{C}$ exhibited a texture closer to that of the control group, and, therefore, such conditions could be applied to manufacture glutenfree noodles.

Cooking quality Cooking quality is important feature of noodles and it encompasses the following characteristics: (a) water absorption indicating water uptake during cooking and (b) cooking loss, related to solid leaching during cooking, considered as an indicator of the overall performance of the cooking process. Fig. 1 shows the results of water absorption and cooking loss of rice noodles after adding $6 \% \mathrm{HPMC}$ at 3 levels of viscosity to the rice flour, and kneading with dough water at room temperature or $80^{\circ} \mathrm{C}$.

Water absorption showed a decrease for noodles prepared with dough water at $80^{\circ} \mathrm{C}$ compared to that prepared with water at room temperature. When water at high temperatures is used, the noodles do not absorb as much water because HPMC rapidly gels and 

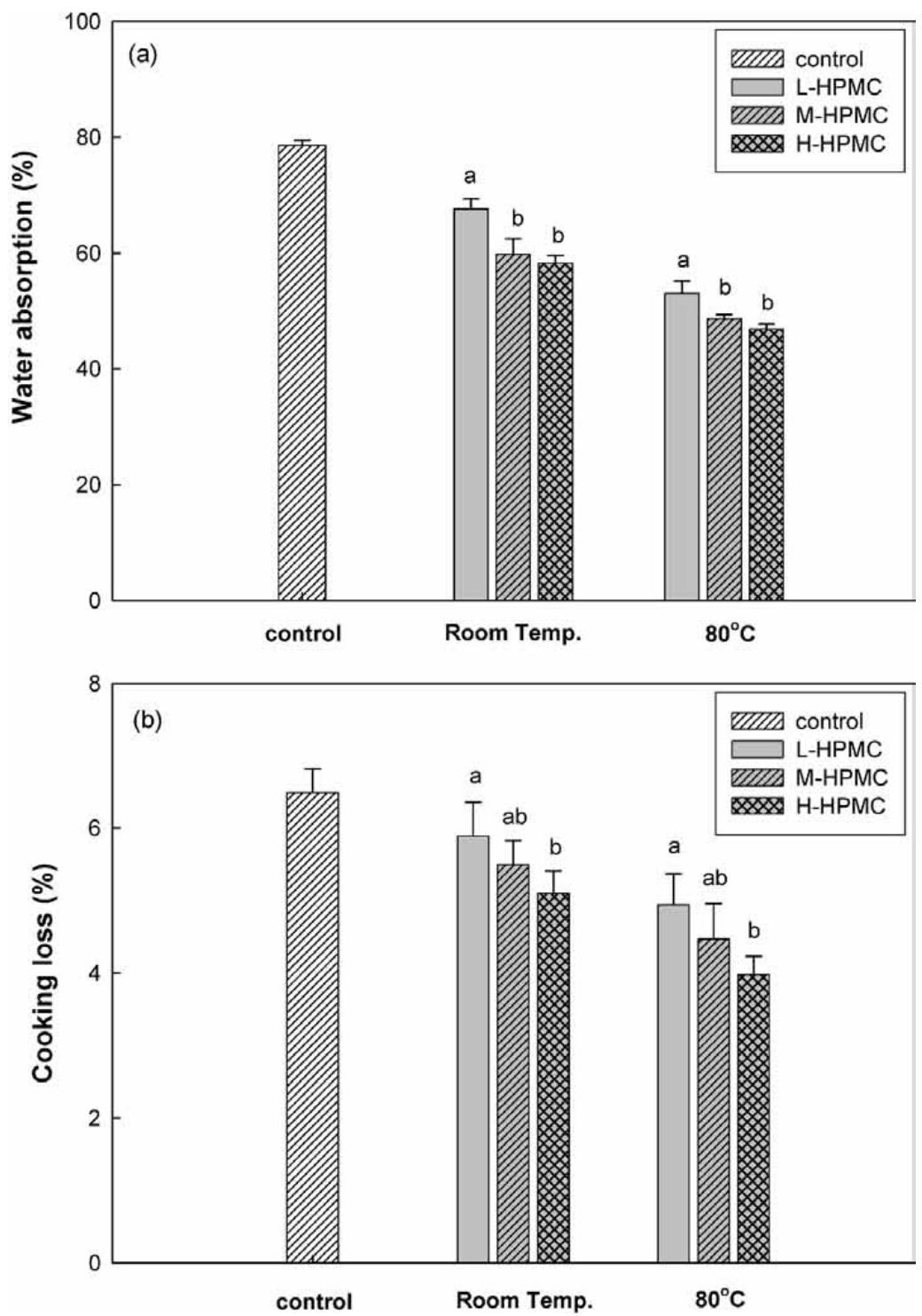

Fig. 1. Effects of HPMC (6\%) on the water absorption (a) and cooking loss (b) of rice noodles prepared with dough water at room temperature and $80^{\circ} \mathrm{C}$

develops a coating layer (Lee et al., 2010; Purnima and Ramasarma, 2012). This is also accompanied by lower cooking loss, which is a measure of the elution of solid content during cooking.

The high cooking loss for noodles is undesirable as it represents high solubility of starch. This results in turbid cooking water and sticky mouthfeel (Bhattacharya et al., 1999). Less than $7-8 \%$ cooking loss is acceptable according to Dick and Youngs (1998). Compared to the control group, the HPMC-containing group showed significantly lower cooking loss; the value dropped to a greater degree at higher levels of HPMC viscosity. Purnima et al. (2012) reported that HPMC forms a network around the starch granules, possibly encapsulating the starch-protein matrix, and, contributing to the lower cooking loss. H-HPMC recorded the lowest water absorption and cooking loss, as it had the highest viscosity among the 3 types of HPMC, thereby forming the most effective coating layer.
Sensory evaluation The results of sensory evaluation of rice noodles containing different HPMCs are shown in Table 4. It displays the results for 6 parameters (color, odour, taste, texture, appearance and overall acceptability), for noodles prepared with dough water at room temperature and $80^{\circ} \mathrm{C}$. The scores for color of the rice noodles with HPMC were significantly increased addition compared to that of the control $(\mathrm{p}<0.05)$, regardless of temperature. Marco and Rocell (2008) reported that rice breads contained with HPMC showed a significant enhancement in the L value of the crumb compared to non-HPMC breads. The scores for taste, and texture in case of HPMC-containing rice noodles were lower compared to those of the control, but as the viscosity of added HPMC increased, the scores for texture and taste increased. Notably the noodles prepared with high-viscosity HPMC (H-HPMC) and dough water at $80^{\circ} \mathrm{C}$ had similar scores for texture (6.4) and taste (5.9), compared to the control (6.8 and 5.7, respectively). 
Table 4. Sensory analysis of HPMC type and water temperature on the textural properties of rice noodles

\begin{tabular}{|c|c|c|c|c|c|c|c|}
\hline Sample & & color & odour & taste & texture & appearance & $\begin{array}{c}\text { overall } \\
\text { acceptability }\end{array}$ \\
\hline Control $^{1)}$ & & $3.10 \pm 1.97^{\mathrm{c}}$ & $4.22 \pm 1.96^{\mathrm{c}}$ & $5.66 \pm 1.42^{\mathrm{a}}$ & $6.78 \pm 1.62^{\mathrm{a}}$ & $6.78 \pm 1.77^{\mathrm{a}}$ & $5.67 \pm 1.42^{\mathrm{ab}}$ \\
\hline \multirow[t]{2}{*}{ L-HPMC ${ }^{2)}$} & $\mathrm{RT}^{3)}$ & $7.70 \pm 1.77^{\mathrm{a}}$ & $4.90 \pm 2.96^{\mathrm{a}}$ & $2.00 \pm 0.47^{\mathrm{c}}$ & $2.40 \pm 0.52^{\mathrm{d}}$ & $2.70 \pm 1.70^{\mathrm{d}}$ & $3.50 \pm 2.32^{\mathrm{cc}}$ \\
\hline & $80^{\circ} \mathrm{C}$ & $5.70 \pm 1.77^{\mathrm{b}}$ & $4.10 \pm 2.23^{b}$ & $2.70 \pm 0.95^{\mathrm{c}}$ & $3.40 \pm 0.97^{\mathrm{cd}}$ & $3.40 \pm 1.51^{\mathrm{cd}}$ & $3.20 \pm 1.03^{\mathrm{d}}$ \\
\hline \multirow[t]{2}{*}{ M-HPMC } & RT & $6.70 \pm 1.64^{\mathrm{ab}}$ & $4.30 \pm 2.45^{\mathrm{ab}}$ & $2.40 \pm 0.52^{\mathrm{c}}$ & $3.10 \pm 0.74^{\mathrm{d}}$ & $4.30 \pm 1.77^{\mathrm{cd}}$ & $3.60 \pm 1.35^{\mathrm{cc}}$ \\
\hline & $80^{\circ} \mathrm{C}$ & $6.00 \pm 1.49^{\mathrm{ab}}$ & $5.30 \pm 2.41^{\mathrm{ab}}$ & $4.50 \pm 1.72^{\mathrm{b}}$ & $4.60 \pm 2.01^{\mathrm{bc}}$ & $4.40 \pm 2.76^{\mathrm{cd}}$ & $4.90 \pm 2.02^{\mathrm{bc}}$ \\
\hline \multirow[t]{2}{*}{ H-HPMC } & RT & $5.70 \pm 2.00^{\mathrm{b}}$ & $5.40 \pm 2.27^{\mathrm{b}}$ & $4.20 \pm 0.63^{\mathrm{b}}$ & $4.80 \pm 1.99^{\mathrm{b}}$ & $4.80 \pm 1.69^{\mathrm{bc}}$ & $4.50 \pm 1.18^{\mathrm{cc}}$ \\
\hline & $80^{\circ} \mathrm{C}$ & $5.50 \pm 2.27^{\mathrm{b}}$ & $4.30 \pm 1.83^{\mathrm{b}}$ & $5.90 \pm 2.33^{\mathrm{a}}$ & $6.40 \pm 1.62^{\mathrm{a}}$ & $6.40 \pm 1.51^{\mathrm{ab}}$ & $6.90 \pm 1.97^{\mathrm{a}}$ \\
\hline
\end{tabular}

\footnotetext{
${ }^{1)}$ control: rice flour + gluten.

${ }^{2)}$ Rice noodles contain 6\% HPMC.

${ }^{3)}$ The temperature of the water used to knead the dough was either room temperature (RT) or $80^{\circ} \mathrm{C}$

${ }^{a-d}$ Means with same letter within a column indicate no significant difference $(\mathrm{p}<0.05)$.
}

Samples containing HPMC and prepared using water at room temperature fared poorer than the control with respect to texture and taste. However, both texture and taste improved for the noodles prepared using dough water at $80^{\circ} \mathrm{C}$. Compared to the control, H-HPMC-containing samples had high scores for color, odour, texture, and taste. Mushy texture is one of the critical quality problems associated with rice noodles. The addition of H-HPMC and use of dough water at $80^{\circ} \mathrm{C}$ had a beneficial effect on the texture because of the interaction of HPMC with the starch granule. These results indicated that addition of H-HPMC did not affect the overall acceptability of noodles because of similar mouthfeel and appearance.

From the results, it can be concluded that addition of $6 \%$ $\mathrm{H}-\mathrm{HPMC}$ and kneading with water at $80^{\circ} \mathrm{C}$ was shown to be the most effective protocol to improve the quality of gluten-free ricebased noodles.

Acknowledgments This study was supported by a grant from the Samsung Fine Chemicals Co., Ltd, Korea and Korea University.

\section{References}

Bean, M. M. and Nishita, K. (1985). Rice flour for baking. In "Rice: chemistry and Technology" ed. by B.O. Juliano. American Association of Cereal Chemists, St. Paul, pp. 539

Bell, D. A. (1990). Methyl cellulose as a structure enhancer in bread baking. Cereal Foods World, 35, 1001-1006.

Bhattacharya, M., Zee, S. Y., and Corke, H. (1999). Physicochemical properties related to quality of rice noodles. Cereal Chem., 76, 861-867.

Cham, S. and Suwannaporn, P. (2010). Effect of hydrothermal treatment of rice flour on various rice noodles quality. J. Cereal Sci., 51, 284-291.

Dick, J. W. and Youngs, V. L. (1988). Evaluation of durum wheat semolina and pasta in the United States, In "Durum Wheat: Chemistry and Technology" ed. by G. Fabriani and C. Lintas. American Association of Cereal Chemists, St. Paul, pp 237-248.

Farzi, M., Saffari, M. M., and Emam-Djomeh, Z. (2013). Effects of sugar, starch and HPMC concentrations on textural properties of reduced-sugar sponge cakes. J. Food Sci. Tech., in press.

Gallagher, E., Gormley. T. R., and Arendt, E. K. (2004). Recent advances in the formulation of gluten-free cereal-based products. Trends Food Sci. Tech., 15, 143-152.

Han, H. M., Cho, J. H., and Koh, B. K. (2011). Processing properties of korean rice varieties in relation to rice noodle quality. Food Sci. Biotechnol., 20, 1277-1282.

Huang, J. C., Knight, S., and Goad, C. (2001). Model prediction for sensory attributes of nongluten pasta. J. Food Quality, 24, 495-511.

Jeya, C., Henry, K., and Thondre, P. S. (2001). The glycaemic index: concept, recent developments and its impact on diabetes and obesity. In "Access Not Excess" ed. by C. Pasternak. Smith-Gordon and Company, Cambs, pp. 154-175.

Jung, B. M., Park, S. O., and Shin, T. S. (2009). Development and quality characteristics of rice noodles made with added Capsosiphon fulvescens powder. Korean J. Food Cookery Sci., 25, 180-188.

Kim, H. S., Turowski, M., Anderson, W. H. K., Young, S. A., Kim, Y. K., and Yokoyama, W. (2011). Supplementation of hydroxypropyl methylcellulose into yeast leavened all-whole grain barley bread potentiates cholesterol-lowering effect. J. Agric. Food Chem., 59, 76727678.

Kim, Y. and Yokoyama, W. H. (2011). Physical and sensory properties of all-barley and all-oat breads with additional hydroxypropyl methylcellulose (HPMC) $\beta$-glucan. J. Agric. Food Chem., 59, 741-746.

Kulp, K., Hepburn, F. N., and Lehmann, T. A. (1974). Preparation of bread without gluten. Bakers Digest, 48, 34-37.

Lai, H. M. (2002). Effects of rice properties and emulsifiers on the quality of rice pasta. J. Sci. Food Agr., 82, 203-216.

Lazaridou, A., Duta, D., Papageorgiou, M., Belc, N., and Biliaderis, C. G. (2007). Effects of hydrocolloids on dough rheology and bread quality parameters in gluten-free formulations. J. Food Eng., 79, 1033-1047.

Lee, S. W., Kim, H. S., Kim, Y. K., Beak, H. H., and Park, H. J. (2010). Application of HPMC for the food industry. Food Sci. Industry, 43, 7684. 
Li, M., Zhang, J. H., Zhu, K. X., Peng, W., Zhang, S. K., Wnag, B., Zhu, Y. J., and Zhou, H. M. (2012). Effect of superfine green tea powder on the thermodynamic, rheological and fresh noodle making properties of wheat flour. LWT-Food Sci. Technol., 46, 23-28.

Marco, C. and Rosell, C. M. (2008). Bread making performance of protein enriched, gluten-free breads. Eur. Food Res. Technol., 227, 1205-1213.

Meadows, F. and Barton, F. E., II. (2002). Determination of rapid visco analyser parameters in rice by near-infrared spectroscopy. Cereal Chem. 79, 563-566.

Moore, M. M., Heinbockel, M., Dockery, P., Ulmer, H. M., and Arendt, E. K. (2006). Network formation in gluten-free bread with application of transglutaminase. Cereal Chem., 83, 28-36.

Murray, J. A. (1999). The widening spectrum of celiac disease. Am. J. Clin. Nutr., 69, 354-365.

Purnima, C., Ramasarma, P. R., and Prabhasankar, P. (2012). Studies on effect of additives on protein profile, microstructure and quality characteristics of pasta. J. Food Sci. Tech., 49, 50-57.

Raina, C. S., Singh, S., Bawa, S., and Saxena, D. C. (2005). Textural characteristics of pasta made from rice flour supplemented with proteins and hydrocolloids. J. Texture Stud., 36, 402-420.

Rosell, C. M., Yokoyamab, W., and Shoemaker, C. (2011). Rheology of different hydrocolloids-rice starch blends. Effect of successive heatingcooling cycles. Carbohyd. Polym., 84, 373-382.

Sabanis, D. and Tzia, C. (2011). Effect of hydrocolloids on selected properties of gluten-free dough and bread. Food Sci. Technol. Int., 17, 279-291.

Yalcin, S. and Basman, A. (2008). Effect of gelatinisation level, gum and transglutaminase on the quality characteristics of rice noodle. Int. J. Food Sci Tech., 43, 1637-1644.

Yang, Y. and Tao, W. Y. (2008). Effects of lactic acid fermentation on FTIR and pasting properties of rice flour. Food Res. Int., 41, 937-940. 